Baseline

\title{
Metal pollution and its biological effects in swimming crab Portunus trituberculatus by NMR-based metabolomics
}

\author{
Deliang $\mathrm{Yu}^{\mathrm{a}}$, Xiao Peng ${ }^{\mathrm{a}, *}$, Chenglong $\mathrm{Ji}^{\mathrm{b}, \mathrm{c}, \mathrm{d}}$, Fei $\mathrm{Li}^{\mathrm{c}, \mathrm{d}}$, Huifeng $\mathrm{Wu}^{\mathrm{b}, \mathrm{c}, \mathrm{d}, * *}$ \\ ${ }^{\text {a }}$ Key Laboratory of Optoelectronic Devices and Systems of Ministry of Education and Guangdong Province, College of Physics and Optoelectronic Engineering, Shenzhen \\ University, Shenzhen 518060, PR China \\ ${ }^{\mathrm{b}}$ Laboratory for Marine Fisheries Science and Food Production Processes, Qingdao National Laboratory for Marine Science and Technology, Qingdao 266237, PR China \\ ${ }^{\mathrm{c}}$ CAS Key Laboratory of Coastal Environmental Processes and Ecological Remediation, Yantai Institute of Coastal Zone Research (YIC), Chinese Academy of Sciences \\ (CAS); Shandong Key Laboratory of Coastal Environmental Processes, YICCAS, Yantai 264003, PR China \\ ${ }^{\mathrm{d}}$ Center for Ocean Mega-Science, Chinese Academy of Sciences, Qingdao 266071, PR China
}

\section{A R T I C L E I N F O}

\section{Keywords:}

Metal pollution

Portunus trituberculatus

Biological effects

Metabolomics

\begin{abstract}
A B S T R A C T
Metal pollution in the Bohai Sea in China has posed a potential risk on marine organisms. In this work, crabs (Portunus trituberculatus) were sampled from four sites, namely a reference (site 3934) and three metal-polluted (sites 6151, 6351, and 3562) sites, located in the Bohai Sea. Metal concentrations in crab gill tissues were measured using inductively coupled plasma mass spectrometry. $\mathrm{Cu}, \mathrm{Zn}$, and $\mathrm{Cd}$ in crab samples from S3562 presented the highest concentrations. Particularly, $\mathrm{Cu}$ concentration exceeded the marine biological quality standard II. Cd contents in crab samples from all metal-polluted sites exceeded the marine biological quality standard I. Nuclear magnetic resonance-based metabolomics indicated metal pollution-induced immune stresses in crab samples from all metal-polluted sites. Metal pollution in S6151 and S6351 disturbed energy metabolism through differential pathways. For crab samples from S3562, the metabolic profile suggested that metal pollution mainly induced osmotic stress.
\end{abstract}

Because of industrial discharges, there are huge amounts of metal contaminants discharged into the Bohai Sea in China. Therefore, metal pollution in the Bohai Sea has become a serious marine environmental problem posing a threat on marine organisms (Wang et al., 2019; Xu et al., 2019). Significant accumulation of metals has been detected in multiple marine samples, including seawater, sediment, and organisms (Chen et al., 2017; Han et al., 2018; Wang et al., 2019). Wang et al. (2019) reported that metals, such as $\mathrm{Cd}, \mathrm{Zn}$, and $\mathrm{Pb}$, were main metal contaminants in seawater sampled in the Liaodong Bay located in the Bohai Sea. Among metal contaminated marine organisms, some species are consumed as seafood by residents. For example, the significant accumulation of $\mathrm{Cd}$ and As was found in the edible shrimp Crangon affinis sampled from the Laizhou Bay and Yellow River Estuary (Ji et al., 2016; Xu et al., 2016). Therefore, it is necessary to assess the metal accumulation and its biological effects in marine organisms in the Bohai Sea.

The swimming crab (Portunus trituberculatus) is one of the marine aquaculture crab species in the Bohai Sea in China (Feng et al., 2018;
Yuan et al., 2019). The production of $P$. trituberculatus was up to 110,000 tons in China in 2015 (FDAMC, 2016). Because of metal pollution in the Bohai Sea, metal accumulation in this edible species, crab $P$. trituberculatus, should be a matter of concern. In addition, it is necessary to characterize metal-induced biological effects in $P$. trituberculatus. As a matter of fact, crab $P$. trituberculatus has been frequently used as an experimental animal to elucidate toxicological effects of marine contaminants, such as cadmium (Cd), benzo[a]pyrene, tamoxifen, and oxytetracycline (Liu et al., 2019; Ren et al., 2017; Wen and Pan, 2015; Xiang et al., 2013). As reported, two metallothioneins (MT-1 and MT-2) were found to perform important functions in spermiogenesis and testis detoxification in P. trituberculatus exposed to Cd for $96 \mathrm{~h}$ (Xiang et al., 2013).

As an omics technique, metabolomics basically focuses on end products of metabolism, metabolites $(<1000 \mathrm{Da})$, to evaluate the metabolic perturbations that may be used to elucidate biological effects caused by pollutants (Cappello et al., 2013; Cappello et al., 2018; Caricato et al., 2019; Ji et al., 2019; Maisano et al., 2017; Song et al.,

\footnotetext{
* Corresponding author.

** Correspondence to: H. Wu, Laboratory for Marine Fisheries Science and Food Production Processes, Qingdao National Laboratory for Marine Science and Technology, Qingdao 266237, PR China.

E-mail addresses: pengxiao_px@szu.edu.cn (X. Peng), hfwu@yic.ac.cn (H. Wu).
} 


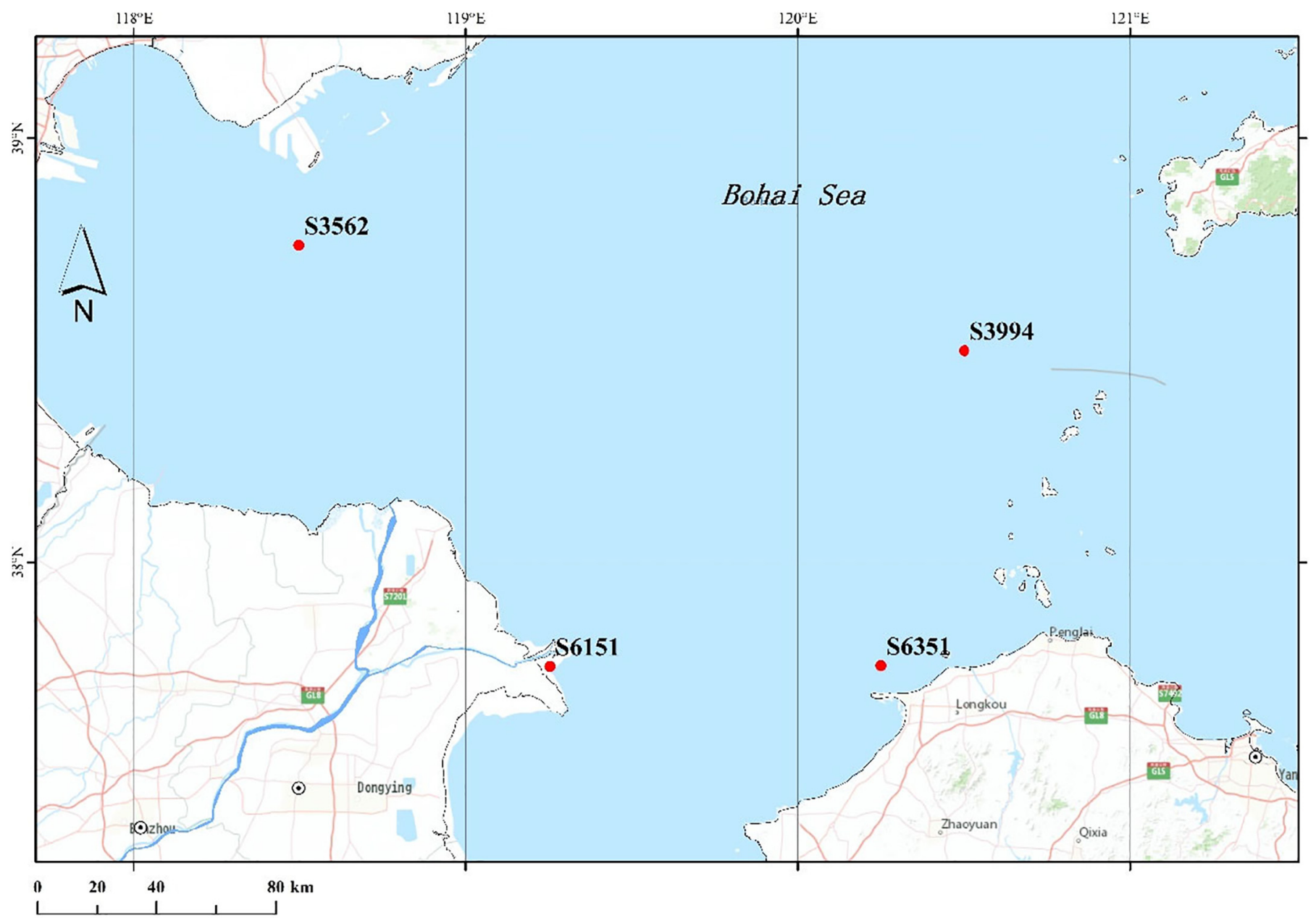

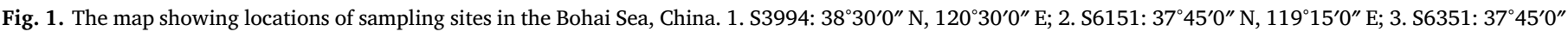
$\mathrm{N}, 120^{\circ} 15^{\prime} 0^{\prime \prime} \mathrm{E}$; 4. S3562: $38^{\circ} 45^{\prime} 0^{\prime \prime} \mathrm{N}, 118^{\circ} 30^{\prime} 0^{\prime \prime}$ E.

2016; Vignet et al., 2019). As nuclear magnetic resonance (NMR) is rapid and nondestructive and can provide detailed structural and quantitative information of metabolites, it has been widely used in environmental metabolomics. In recent years, NMR-based metabolomics has been extensively used in ecotoxicology (Cappello et al., 2016a, 2016b). In this work, inductively coupled plasma mass spectrometry (ICP-MS) was applied to measure metal concentrations, and NMR-based metabolomics was used to test metabolic alterations to elucidate biological effects induced by metal pollution in crab P. trituberculatus collected from metal-polluted sites along the Bohai Sea.

The crabs, $P$. trituberculatus, were collected from four sites, including reference site 3994 (S3994: $38^{\circ} 30^{\prime} 0^{\prime \prime} \mathrm{N}, 120^{\circ} 30^{\prime} 0^{\prime \prime} \mathrm{E}$ ) and three typical metal-polluted sites, 6151 (S6151: $37^{\circ} 45^{\prime} 0^{\prime \prime} \mathrm{N}, 119^{\circ} 15^{\prime} 0^{\prime \prime} \mathrm{E}$ ), 6351 (S6351: $37^{\circ} 45^{\prime} 0^{\prime \prime} \mathrm{N}, 120^{\circ} 15^{\prime} 0^{\prime \prime} \mathrm{E}$ ), and 3562 (S3562: $38^{\circ} 45^{\prime} 0^{\prime \prime} \mathrm{N}$, $\left.118^{\circ} 30^{\prime} 0^{\prime \prime} \mathrm{E}\right)$, located along the Laizhou Bay and Bohai Bay in the Bohai Sea in August 2017 (Fig. 1). Among these sampling sites, S3994 is relatively far away from sewage outfalls, and therefore chosen as the reference site (Liang et al., 2011). S6151 is adjacent to the Yellow River Estuary, where metal pollution was present because of discharges from both industries and agricultural lands located on riversides along the Yellow River (Ji et al., 2016). Longkou city is abundant with gold mining industries, which has led to metal pollution in S6351 (Liang et al., 2011). S3562 faces several industrial parks located in Tangshan city along the coastline of the Bohai Bay. Therefore, these three sampling sites, S6151, S6351, and S3562 were potentially polluted by metals from discharges and selected as polluted sites. For each sampling site, eight crabs with similar sizes $(\sim 80 \mathrm{~g})$ were sampled and their gill tissues were dissected immediately and frozen in liquid nitrogen. After they were transported to the laboratory, crab gill tissues were stored at $-80{ }^{\circ} \mathrm{C}$ before metal determination and metabolite extraction.

Metabolites in crab gill tissues $(n=8)$ were extracted using a methanol/water/chloroform protocol (Ji et al., 2016). In brief, each gill sample ( $\sim 100 \mathrm{mg}$ ) was ground into a homogeneous powder in liquid nitrogen. Then the powder of gill sample was homogenized by the high throughput homogenizer (Precellys 24, Bertin Technologies, France). Solvents, including methanol $(4 \mathrm{~mL} / \mathrm{g})$, water $(0.85 \mathrm{~mL} / \mathrm{g})$, and chloroform $(2 \mathrm{~mL} / \mathrm{g})$, were used for metabolite extraction. After being shaken and centrifuged $(3000 \mathrm{~g})$ for $5 \mathrm{~min}$ at $4{ }^{\circ} \mathrm{C}$, the upper polar layer containing metabolites $(<1000 \mathrm{Da})$ was transferred to the glass vial and dried using a centrifugal concentrator. The dried metabolite extract of each crab gill sample was dissolved in $600 \mu \mathrm{L}$ of $100 \mathrm{mM}$ phosphate buffer $\left(\mathrm{Na}_{2} \mathrm{HPO}_{4}\right.$ and $\mathrm{NaH}_{2} \mathrm{PO}_{4}$ with $0.5 \mathrm{mM}$ TSP and pH 7.0) in $\mathrm{D}_{2} \mathrm{O}$. The solution was vortexed and centrifuged $(3000 \mathrm{~g})$ for $5 \min \left(4{ }^{\circ} \mathrm{C}\right)$. Finally, $550 \mu \mathrm{L}$ of the solution was pipetted into an NMR tube $(5 \mathrm{~mm})$ for ${ }^{1} \mathrm{H}$ NMR spectroscopy measurement on a Bruker AV 500 NMR spectrometer $\left(25^{\circ} \mathrm{C}\right)$ (Ji et al., 2016).

After phase and baseline correction, and calibration (TSP at $0.0 \mathrm{ppm}$ ), all the ${ }^{1} \mathrm{H}$ NMR spectra were converted into a data matrix using ProMetab software in MatLab (V7.0, The MathWorks, Natick, MA, USA) (Viant et al., 2003). Details of NMR spectral data processing were previously described (Zhang et al., 2011).

The preprocessing method, mean-centering, was employed to ${ }^{1} \mathrm{H}$ NMR spectral data prior to further multivariate data analysis. Principal component analysis (PCA) was applied for separating crab samples 
from the S3994, S6151, S6351, and S3562 in the Bohai Sea. The supervised pattern recognition methods, partial least squares discriminant analysis (PLS-DA), and orthogonal projection to latent structure with discriminant analysis (O-PLS-DA), were subsequently conducted on NMR spectral data to discover metabolic responses induced by metal pollution. The detailed information for PLS-DA and O-PLS-DA was described by Feng et al. (2013). Metabolites were assigned using the software, Chenomx (Evaluation Version, Chenomx Inc., Edmonton, Alberta, Canada) and based on publications (Cappello et al., 2013; Caricato et al., 2019).

In the Bohai Sea, metals/metalloids, $\mathrm{As}, \mathrm{Cd}, \mathrm{Cr}, \mathrm{Cu}, \mathrm{Mn}, \mathrm{Ni}, \mathrm{Pb}$, and Zn were potential metal pollutants in multiple samples, such as seawater, sediment, and biota (Gao et al., 2014; Ji et al., 2016; Xu et al., 2016; Zhang et al., 2012). In this work, therefore, concentrations of these metals/metalloids were measured in crab samples. Crab gill tissue samples $(n=8)$ were weighed accurately and digested in concentrated $\mathrm{HNO}_{3}$ at $80{ }^{\circ} \mathrm{C}$ for $12 \mathrm{~h}$. Metal concentrations in crab samples were measured using the ICP-MS technique (Agilent $7700 \times$ ). Details for metal determination and data analysis were described in Ji et al. (2016).

The crab $P$. trituberculatus is delicious and full of nutrition. Therefore, this species is widely cultured in marine aquaculture along the Bohai Sea (Yuan et al., 2019). Because of industrial discharges, the observable metal pollution in the Bohai Sea has posed risks on marine aquaculture species (Gao et al., 2014; Zhang et al., 2012). However, there is little information about metal concentrations in the crab $P$. trituberculatus from the Bohai Sea. In this study, metal concentrations were tested in gill tissues of crab $P$. trituberculatus sampled from the Bohai Sea (Table 1). To evaluate the metal pollution in these four sampling sites, the integrated metal contamination (IMC) was compared using the equation (Liu and Wang, 2012):

Integrated metal contamination $=\sum_{i=0}^{m} C_{\text {contaminated }}^{i}-C_{\text {clean }}^{i}$

In this equation, $C_{\text {contaminated }}{ }^{i}$ is the concentration of the ith metal (metalloid) in a contaminated crab sample, and $C_{\text {clean }}{ }^{i}$ is the reference value for the ith metal/metalloid in a crab sample from the reference site, S3994. $\mathrm{m}$ is the total number of all metal (metalloid) that a crab was exposed to, i.e., $\mathrm{m}=8$ in this study. The IMC values demonstrated that crab samples from S3562 had the highest metal concentration. Crab samples collected from the reference site, S3994, had the lowest metal concentration. Overall, the order of metal contents from four sampling sites was S3562 > S6351 > S6151 > S3994. In the crab samples from $\mathrm{S} 3562$ located in the Bohai Bay, $\mathrm{Cu}, \mathrm{Zn}$, and $\mathrm{Cd}$ showed highest mean concentrations (Table 1 ). However, only Cd concentration presented the statistical significance $(P<0.05)$. In particular, the mean concentration of $\mathrm{Cu}$ in crab samples collected from S3562 exceeded the marine biological quality standard II (National Standard of
PR China 2001). A couple of studies reported that $\mathrm{Cu}, \mathrm{Zn}$, and $\mathrm{Cd}$ posed high ecological risks in the Bohai Bay (Chen et al., 2017; Wang et al., 2017), which was consistent with our data. Concentrations of $\mathrm{Pb}, \mathrm{Ni}$, and Cd in crab gill samples from S6151 located in the Yellow River Estuary were significantly higher than those from the reference site (S3994). In fact, ecological risks of $\mathrm{Pb}$ and $\mathrm{Ni}$ in sediments from the Yellow River Estuary were increased from 2013 because of anthropogenic activities, such as the implementation of Flow-sediment Regulation Scheme (Tian, 2018). In addition, the significant bioaccumulation of Cd was similarly observed in shrimp Crangon affinis in our previous work ( $\mathrm{Ji}$ et al., 2016). Mean concentrations of $\mathrm{Cd}$ in crab samples from all three metal-polluted sites, S6151, S6351, and S3562, exceeded the marine biological quality standard I (National Standard of PR China 2001). Because of the coal- and gold-mining industries close to S6351, Ni was found to be one of main metal contaminants in shrimp C. affinis (Xu et al., 2016), which was also observed in crab samples in this work. These differential metal pollution profiles in the Bohai Sea might cause differential biological effects in crab $P$. trituberculatus.

NMR spectroscopy-based metabolomics has been widely used to measure metabolic responses induced by environmental pollutants in environmental biological samples (Cappello et al., 2018; Caricato et al., 2019; Fasulo et al., 2012; Kwon et al., 2012; Vignet et al., 2019). One representative ${ }^{1} \mathrm{H}$ NMR spectrum of crab gill tissue extracts from S3994 is displayed in Fig. 2. In total, 36 metabolites were identified in crab samples. These metabolites included organic osmolytes (dimethylamine, dimethylglycine, betaine, taurine, hypotaurine, and homarine), energy storage compounds (ATP, glucose, and glycogen), organic acids (lactate, 2-hydroxyglutarate, acetate, succinate, malonate, and fumurate), and amino acids (isoleucine, leucine, valine, threonine, alanine, glutamate, lysine, glycine, histidine, etc.). After PCA, significant $(P<0.05)$ separations between reference (S6334) and metal pollution-exposed groups (S6151, S6351, and S3572) were found along both PC1 and PC2 axes (Fig. 3). However, there were no significant separations between metal pollution-exposed groups. Therefore, the supervised patter recognition method, O-PLS-DA, was performed on the NMR spectral data from the reference (S3994) and metal pollutionexposed groups (S6151, 6351, and S3572), respectively, to detect metabolic differences related to metal pollution (Fig. 4).

O-PLS-DA achieved pairwise classifications between reference (S3994) and metal pollution-exposed groups (S6151, S6351, and S3572), with reliable $Q^{2}$ values $>0.5$ (Fig. 4A, B, and C), respectively. Then, metabolic differences between reference (S3994) and metal pollution-exposed groups (S6151, S6351, and S3562) were presented in corresponding loading plots (Fig. 4D, E, and F) and summarized in Table 2. Crab samples from S6151 had higher levels of malonate, phosphocholine, and taurine and lower levels of branched chain amino acids (BCAAs: valine, isoleucine, and leucine), glutamate, glutamine, and acetoacetate than those in crab samples from the reference site,

Table 1

Metal/metalloid concentrations in gill tissues from crab Portunus trituberculatus sampled from four sampling sites, including the reference site, the middle of the Bohai Sea (S3994), and metal-polluted sites, the Yellow River Estuary (S6151), Longkou (S6351), and the Bohai Bay (S3562), in the Bohai Sea.

\begin{tabular}{|c|c|c|c|c|}
\hline \multirow[t]{2}{*}{ Metal/metalloid concentration ${ }^{\mathrm{a}}$} & \multicolumn{3}{|l|}{ Sampling site } & \multirow[b]{2}{*}{ S3562 } \\
\hline & S3994 & S6151 & S6351 & \\
\hline $\mathrm{Pb}$ & $0.121 \pm 0.023$ & $0.195 \pm 0.054^{* *}$ & $0.078 \pm 0.033$ & $0.131 \pm 0.047$ \\
\hline $\mathrm{Cr}$ & $0.441 \pm 0.102$ & $0.493 \pm 0.041$ & $0.459 \pm 0.033$ & $0.441 \pm 0.094$ \\
\hline Mn & $6.755 \pm 4.079$ & $7.786 \pm 2.185$ & $6.857 \pm 5.120$ & $7.334 \pm 5.652$ \\
\hline $\mathrm{Ni}$ & $0.356 \pm 0.093$ & $0.637 \pm 0.219^{* *}$ & $0.629 \pm 0.229^{* *}$ & $0.512 \pm 0.293$ \\
\hline $\mathrm{Cu}$ & $20.382 \pm 11.719$ & $22.234 \pm 12.038$ & $21.924 \pm 12.563$ & $28.122 \pm 21.989$ \\
\hline $\mathrm{Zn}$ & $6.440 \pm 4.023$ & $5.815 \pm 1.304$ & $6.709 \pm 2.518$ & $8.466 \pm 3.253$ \\
\hline As & $1.517 \pm 0.900$ & $1.515 \pm 0.211$ & $2.279 \pm 0.825$ & $2.162 \pm 0.722$ \\
\hline $\mathrm{Cd}$ & $0.190 \pm 0.098$ & $0.329 \pm 0.072^{*}$ & $0.317 \pm 0.129$ & $0.422 \pm 0.184^{*}$ \\
\hline
\end{tabular}

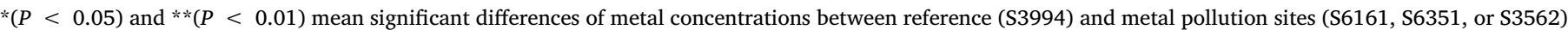
(Student's $t$-test).

${ }^{\text {a }}$ Data are shown as mean \pm standard deviation $(n=8)$. Values are presented as $\mu \mathrm{g} / \mathrm{g}$ wet weight. 


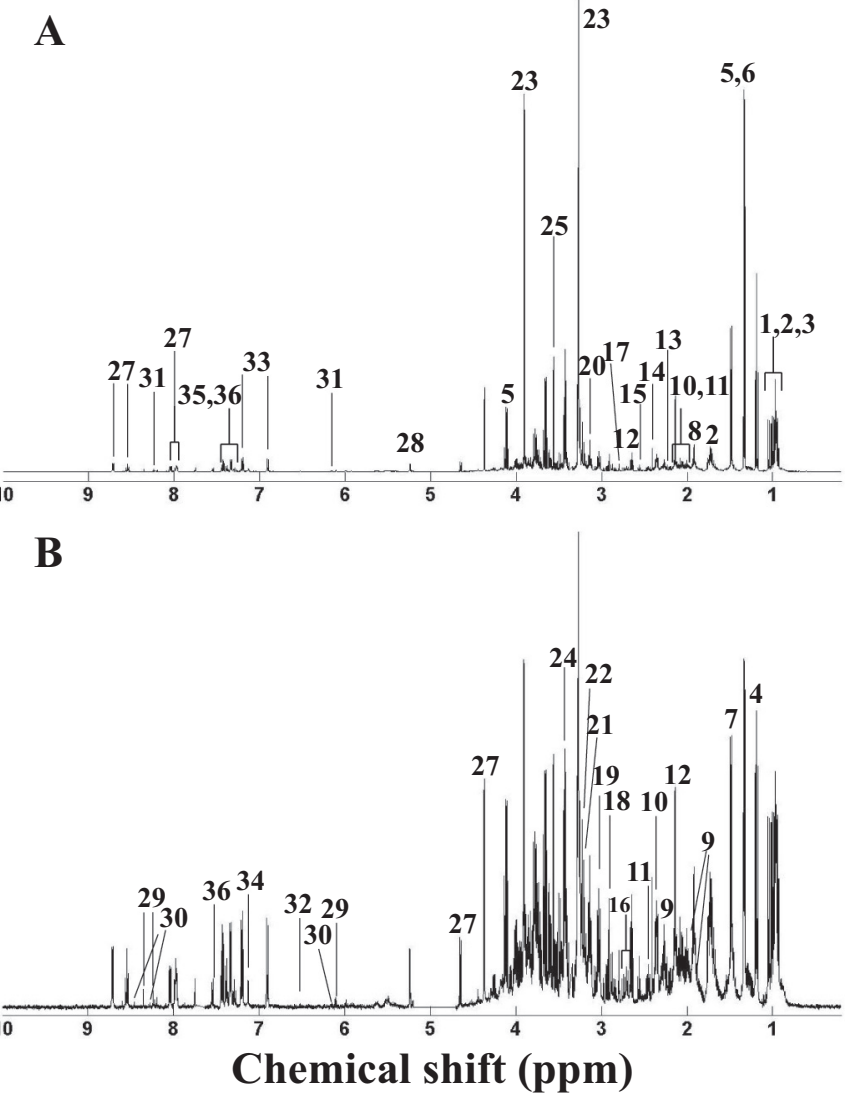

Fig. 2. One representative 1-dimensional $500 \mathrm{MHz}{ }^{1} \mathrm{H}$ NMR spectrum of gill tissue extracts of crab Portunus trituberculatus from the reference site (S3994) in original (A) and generalized transformed (B) forms. Keys: (1) isoleucine, (3) leucine, (3) valine, (4) ethanol, (5) lactate, (6) threonine, (7) alanine, (8) acetate, (9) 2-hydroxyglutarate, (10) glutamate, (11) glutamine, (12) methionine, (13) acetoacetate, (14) succinate, (15) $\beta$-alanine, (16) aspartate, (17) dimethylamine, (18) dimethylglycine, (19) lysine, (20) malonate, (21) choline, (22) phosphocholine, (23) betaine, (24) taurine, (25) glycine, (26) homarine, (27) $\beta$-glucose, (28) $\alpha$-glucose, (29) inosine, (30) AMP, (31) ATP, (32) fumarate, (33) tyrosine, (34) histidine, (35) tryptophan, and (36) phenylalanine.

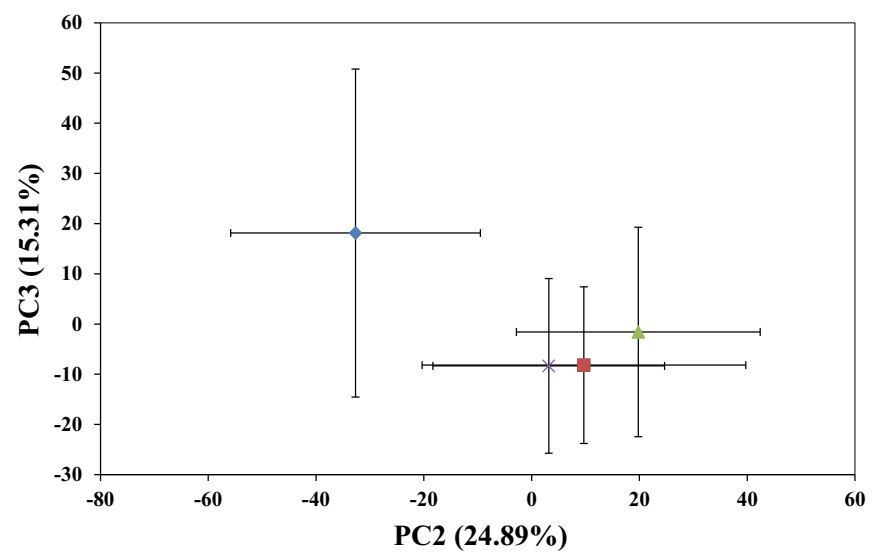

Fig. 3. The score plot of the principal component analysis (PCA) along PC1 and PC2 axes generated from ${ }^{1} \mathrm{H}$ NMR spectra of gill tissue extracts from crab $P$. trituberculatus sampled from S3994 (४), S6151 ( $\square$ ), S6351( $)$ ), and S3562 ( $\times$ ).

S3994 (Fig. 4D). For crab samples collected from S6351, relatively high abundances of glutamine and ATP were found together with low abundances of BCAAs, tyrosine, alanine, lactate, 2-hydroxyglutarate, glucose, and inosine. Metabolic profiles presented higher levels of taurine, glycine, and homarine and lower levels of BCAAs, tyrosine, histidine, phenylalanine, and methionine in crab samples from S3562 than those in samples collected from S3994 (Fig. 4F).

Among these metabolic differences, BCAAs (valine, leucine, and isoleucine) were commonly lower in crab samples from three metalpolluted sites, S6151, S6351, and S3562. BCAAs are important in protein synthesis in immune cells for protecting the host from pathogenic invaders, and therefore play vital roles in the immune system (Calder, 2006; De Simone et al., 2013). The depleted BCAAs implied that the disturbance in the immune system was caused by metal pollution in crab samples from these three metal-polluted sites, S6151, S6351, and S3562. Interestingly, Lu et al. (2020) reported the depleted BCAAs in Cd-polluted shrimp Fenneropenaeus chinensis was also sampled from the Bohai Sea. Compared with crab samples from the reference site (S3994), crab samples from S6151, S6351, and S3562 presented relatively high Cd accumulation, with $P$ values less than (S6151 and S3562) or approximately 0.05 ( $P$ value $=0.09$, S6351). Therefore, depleted BCAAs might be used as metabolic markers for Cd in marine crustaceans, such as shrimp $F$. chinensis and crab $P$. trituberculatus. Phosphocholine is related to energy metabolism and involved in the conversion of ATP and choline into phosphocholine and ADP catalyzed by choline kinase (Ji et al., 2014). As a ketone body, acetoacetate is synthesized from acetyl-coenzyme A (acetyl-CoA) in fatty acid metabolism. Malonate is a competitive inhibitor of succinate dehydrogenase in Krebs cycle (Lu et al., 2020). The elevated phosphocholine and malonate and depleted acetoacetate suggested that metal pollution disrupted energy metabolism by influencing the Krebs cycle and fatty acid metabolism in crabs collected from S6151. The organic osmolyte, taurine, is known to balance the intracellular osmolarity with the environment in marine invertebrates (Viant et al., 2003). The elevated level of taurine meant that the metal pollution in S6151 induced osmotic stress in crabs. Similar to taurine, free amino acids can also be used as osmolytes in marine invertebrates (Viant et al., 2003). Therefore, decreased amino acids, including glutamate, glutamine, and tyrosine, were likely used to compensate for the increased osmolyte, taurine.

For crab samples from S6351, ATP, and 2-hydroxyglutarate were elevated and depleted, respectively. 2-hydroxyglutarate can be converted to $\alpha$-ketoglutaric acid by 2 -hydroxyglutarate dehydrogenase and inhibit ATP synthase (Fu et al., 2015). Therefore, depleted 2-hydroxyglutarate meant the reduced inhibition of ATP synthase, resulting in elevated ATP and depleted glucose in crab samples caused by metal pollution in S6351. The decreased lactate clearly indicated the reduced anaerobiosis in crab samples collected from S6351. Inosine is an intermediate in purine nucleotide reactions and is required for muscle movements (Gómez-Canela et al., 2018). Decreased levels of inosine implied the disruption in muscle movement in crab samples from S6351. The altered amino acids, including glutamine, tyrosine, and alanine, might suggest the disrupted amino acid metabolism in crab samples from S6351. Surprisingly, three known organic osmolytes, including taurine, glycine, and homarine, were simultaneously increased in crab samples from S3562, which indicated obvious osmotic stress induced by metal pollution. However, amino acids, such as tyrosine, histidine, phenylalanine, and methionine, were decreased. These decreased amino acids were probably used to compensate for the increased osmolytes, taurine, glycine, and homarine.

In summary, $\mathrm{Cu}, \mathrm{Zn}$, and $\mathrm{Cd}$ in crab samples from S3562 in the Bohai Bay presented the highest concentrations. In particular, the mean concentration of $\mathrm{Cu}$ in crab samples collected from $\mathrm{S} 3562$ exceeded the marine biological quality standard II (National Standard of PR China 2001). Concentrations of $\mathrm{Pb}, \mathrm{Ni}$, and $\mathrm{Cd}$ in crab gill samples from $\mathrm{S} 6151$ located in the Yellow River Estuary were significantly higher than those from the reference site (S3994). For crab samples collected from S6351, the content of Ni was higher than that from the reference site (S3994). Specifically, mean concentrations of $\mathrm{Cd}$ in crab samples from all three metal-polluted sites, S6151, S6351, and S3562, exceeded the marine biological quality standard I (National Standard of PR China, 2001). 

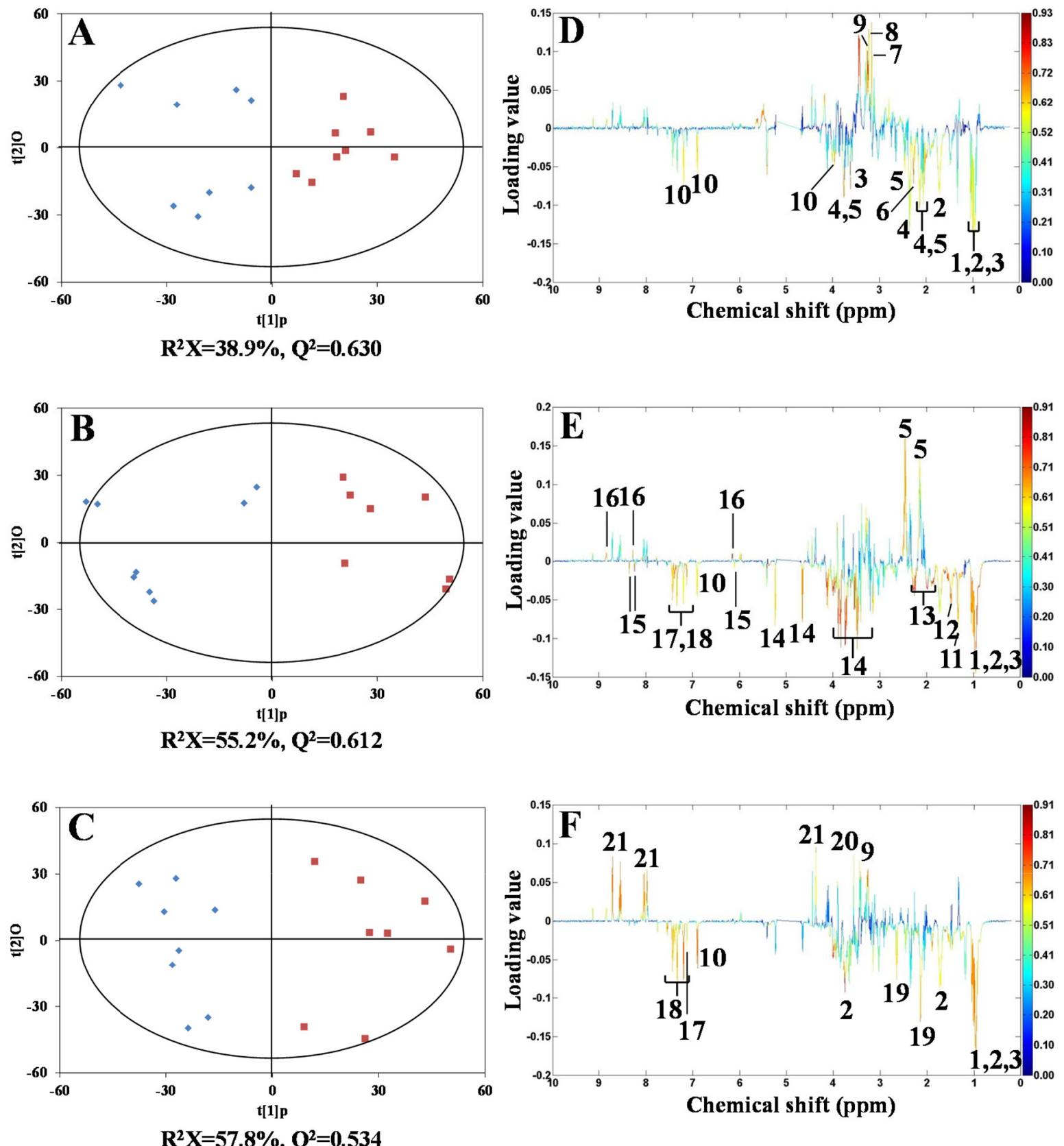

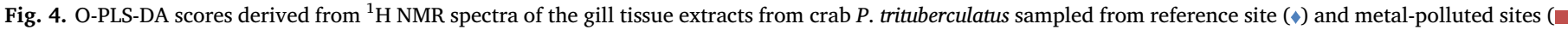

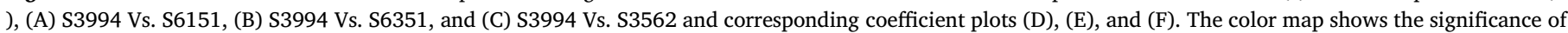

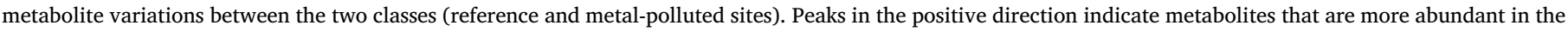

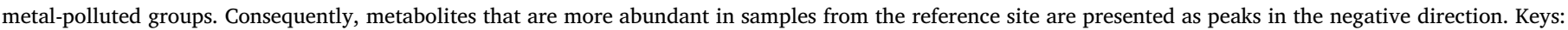

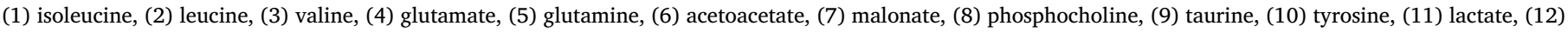
alanine, (13) 2-hydroxyglutarate, (14) glucose, (15) inosine, (16) ATP, (17) histidine, (18) phenylalanine, (19) methionine, (20) glycine, and (21) homarine.

NMR-based metabolomic analysis exhibited the metal pollution-induced immune stress in crab samples collected from all three metalpolluted sites, which might be related to higher levels of $\mathrm{Cd}$ in crab samples. The metal pollution in S6151 and S6351 disturbed energy metabolism through differential pathways. In addition, the decreased inosine implied the disruption in muscle movement in crab samples from S6351. Interestingly, the metabolic profile suggested that metal pollution mainly induced osmotic stress in crab samples from S3562.

\section{CRediT authorship contribution statement}

Deliang Yu:Formal analysis, Writing - original draft.Xiao
Peng:Funding acquisition, Writing - review \& editing, Project administration.Chenglong Ji:Writing - review \& editing.Fei Li:Writing - review \& editing.Huifeng Wu:Supervision, Writing review \& editing, Project administration.

\section{Declaration of competing interest}

The authors declare that they have no known competing financial interests or personal relationships that could have appeared to influence the work reported in this paper. 
Table 2

Relative change trends of metabolites in gill samples of crab $P$. trituberculatus from metal-polluted sites (S6151, S6351, and S3562) when compared with those from the reference site (S3994).

\begin{tabular}{|c|c|c|c|c|}
\hline \multirow[t]{2}{*}{ Metabolites } & \multirow[t]{2}{*}{ Typical chemical shift (ppm) } & \multicolumn{3}{|c|}{ Metal-polluted sites } \\
\hline & & S6151 & S6351 & S3562 \\
\hline Leucine & $0.94(d)$ & $\downarrow$ & $\downarrow$ & $\downarrow$ \\
\hline Isoleucine & $1.00(\mathrm{~d})$ & $\downarrow$ & $\downarrow$ & $\downarrow$ \\
\hline Valine & $1.05(\mathrm{~d})$ & $\downarrow$ & $\downarrow$ & $\downarrow$ \\
\hline Lactate & $1.33(d)$ & - & $\downarrow$ & - \\
\hline Alanine & $1.47(\mathrm{~d})$ & - & $\downarrow$ & - \\
\hline 2-hydroxyglutarate & $1.85(\mathrm{~m})$ & - & $\downarrow$ & - \\
\hline Glutamate & $2.10(\mathrm{~m})$ & $\downarrow$ & - & - \\
\hline Glutamine & $2.14(\mathrm{~m})$ & $\downarrow$ & $\uparrow$ & $\downarrow$ \\
\hline Methionine & $2.17(\mathrm{~m})$ & - & - & - \\
\hline Acetoacetate & $2.28(\mathrm{~s})$ & $\downarrow$ & - & - \\
\hline Malonate & $3.13(\mathrm{~s})$ & $\uparrow$ & - & - \\
\hline Phosphocholine & $3.22(\mathrm{~s})$ & $\uparrow$ & - & - \\
\hline Taurine & $3.27(\mathrm{t})$ & $\uparrow$ & - & $\uparrow$ \\
\hline Glycine & $3.56(\mathrm{~s})$ & - & - & $\uparrow$ \\
\hline Homarine & $4.37(\mathrm{~s})$ & - & - & $\uparrow$ \\
\hline Glucose & 5.24 (d) & - & $\downarrow$ & - \\
\hline Inosine & $6.11(d)$ & - & $\downarrow$ & - \\
\hline ATP & 6.15 (d) & - & $\uparrow$ & - \\
\hline Tyrosine & $6.90(d)$ & $\downarrow$ & - & $\downarrow$ \\
\hline Histidine & $7.13(\mathrm{~s})$ & - & $\downarrow$ & $\downarrow$ \\
\hline Phenylalanine & $7.33(\mathrm{~m})$ & - & $\downarrow$ & $\downarrow$ \\
\hline
\end{tabular}

$\mathrm{s}=$ singlet, $\mathrm{d}=$ doublet, $\mathrm{t}=$ triplet, and $\mathrm{m}=$ multiplet.

\section{Acknowledgments}

This work was supported by Qingdao National Laboratory for Marine Science and Technology (QNLM201701), NSFC (31771584 and 41806142), and the Young Taishan Scholar Foundation of Shandong Province for Prof. Huifeng Wu (tsqn201812115), and we thank Prof. Mark Viant for the use of ProMetab software.

\section{References}

Calder, P.C., 2006. Branched chain amino acids and immunity. J. Nutr. 136, 288S-293S. Cappello, T., Mauceri, A., Corsaro, C., Maisano, M., Parrino, V., Lo Paro, G., Messina, G., Fasulo, S., 2013. Impact of environmental pollution on caged mussels Mytilus galloprovincialis using NMR-based metabolomics. Mar. Pollut. Bull. 77, 132-139.

Cappello, T., Brandão, F., Guilherme, S., Santos, M.A., Maisano, M., Mauceri, A., Canário, J., Pacheco, M., Pereira, P., 2016a. Insights into the mechanisms underlying mercuryinduced oxidative stress in gills of wild fish (Liza aurata) combining ${ }^{1} \mathrm{H}$ NMR metabolomics and conventional biochemical assays. Sci. Total Environ. 548-549, 13-24.

Cappello, T., Pereira, P., Maisano, M., Mauceri, A., Pacheco, M., Fasulo, S., 2016b. Advances in understanding the mechanisms of mercury toxicity in wild golden grey mullet (Liza aurata) by ${ }^{1} \mathrm{H}$ NMR-based metabolomics. Environ. Pollut. 219, 139-148.

Cappello, T., Giannetto, A., Parrino, V., De Marco, G., Mauceri, A., Maisano, M., 2018. Food safety using NMR-based metabolomics: assessment of the Atlantic bluefin tuna, Thunnus thynnus, from the Mediterranean Sea. Food Chem. Toxicol. 115, 391-397.

Caricato, R., Giordano, M.E., Schettino, T., Maisano, M., Mauceri, A., Giannetto, A., Cappello, T., Parrino, V., Ancora, S., Caliani, I., Bianchi, N., Leonzio, C., Mancini, G., Cappello, S., Fasulo, S., Lionetto, M.G., 2019. Carbonic anhydrase integrated into a multimarker approach for the detection of the stress status induced by pollution exposure in Mytilus galloprovincialis: a field case study. Sci. Total Environ. 690, $140-150$.

Chen, X., Li, S., Yuan, D., Mu, D., Li, Y., 2017. Distribution characteristics of sediment heavy metals in Bohai Bay and its effect factors (in Chinese). Adv. Mar. Sci. 35 (3), 382-391.

De Simone, R., Vissicchio, F., Mingarelli, C., De Nuccio, C., Visentin, S., Ajmone-Cat, M.A., Minghetti, L., 2013. Branched-chain amino acids influence the immune properties of microglial cells and their responsiveness to pro-inflammatory signals. Biochim. Biophys. Acta 1832, 650-659.

Fasulo, S., Iacono, F., Cappello, T., Corsaro, C., Maisano, M., D’Agata, A., Giannetto, A., de Domenico, E., Parrino, V., Lo Paro, G., Mauceri, A., 2012. Metabolomic investigation of Mytilus galloprovincialis (Lamarck 1819) caged in aquatic environments. Ecotoxicol. Environ. Saf. 84, 139-146.

FDAMC (Fisheries Department of Agriculture Ministry of China), 2016. China Fisheries Yearbook. China Agriculture Press, Beijing (in Chinese).

Feng, J., Li, J., Wu, H., Chen, Z., 2013. Metabolic responses of HeLa cells to silica nanoparticles by NMR-based metabolomic analyses. Metabolomics 9, 874-886.
Feng, J., Tian, X., Dong, S., He, R., Zhang, K., Zhang, D., Li, L., Zhang, Q., Zhang, T., 2018. Comparative analysis of the energy fluxes and trophic structure of polyculture ecosystems of Portunus trituberculatus based on Ecopath model. Aquaculture 496, 185-196.

Fu, X., Chin, R.M., Vergnes, L., Hwang, H., Deng, G., Xing, Y., Pai, M.Y., Li, S., Ta, L., Fazlollahi, F., Chen, C., Prins, R.M., Teitell, M.A., Nathanson, D.A., Lai, A., Faull, K.F., Jiang, M., Clarke, S.G., Cloughesy, T.F., Graeber, T.G., Braas, D., Christofk, H.R., Jung, M.E., Reue, K., Huang, J., 2015. Cell Metab. 22, 508-515.

Gao, X., Zhou, F., Chen, C.-T.A., 2014. Pollution status of the Bohai Sea: an overview of the environmental quality assessment related trace metals. Environ. Int. 62, 12-30.

Gómez-Canela, C., Prats, E., Lacorte, S., Raldúa, D., Piña, B., Tauler, R., 2018. Metabolomic changes induced by nicotine in adult zebrafish skeletal muscle. Ecotoxicol. Environ. Saf. 164, 388-397.

Han, D., Zhao, F., Mu, W., Zhang, D., Zhou, D., 2018. Hazard analysis and screening of the prior heavy metals of priority pollution in fish in the Yellow Sea and the Bohai Sea (in Chinese). Prog. Fish. Sci. 39 (1), 46-53.

Ji, C., Zhao, J., Wu, H., 2014. Gender-specific metabolic responses in gonad of mussel Mytilus galloprovincialis to2,2',4,4'-tetrabromodiphenyl ether. Environ. Toxicol. Pharmacol. 37, 1116-1122.

Ji, C., Yu, D., Wang, Q., Li, F., Zhao, J., Wu, H., 2016. Impact of metal pollution on shrimp Crangon affinis by NMR-based metabolomics. Mar. Pollut. Bull. 106, 372-376.

Ji, C., Lu, Z., Xu, L., Li, F., Cong, M., Wu, H., 2019. Evaluation of mitochondrial toxicity of cadmium in clam Ruditapes philippinarum using iTRAQ-based proteomics. Environ. Pollut. 251, 802-810.

Kwon, Y.K., Jung, Y.S., Park, J.C., Seo, J., Choi, M.S., Hwang, G.S., 2012. Characterizing the effect of heavy metal contamination on marine mussels using metabolomics. Mar. Pollut. Bull. 64, 1874-1879.

Liang, N., Yang, L., Dai, J., Pang, X., 2011. Heavy metal pollution in surface water of Linglong gold mining area, China. Procedia Environ. Sci. 10, 914-917.

Liu, F., Wang, W.-X., 2012. Proteome pattern in oysters as a diagnostic tool for metal pollution. J. Hazard. Mater. 239-240, 241-248.

Liu, M., Feng, Q., Francis, D.S., Turchini, G.M., Zeng, C., Wu, X., 2019. Tamoxifen affects the histology and hepatopancreatic lipid metabolism of swimming crab Portunus trituberculatus. Aquat. Toxicol. 213, 105220.

Lu, Z., Wang, S., Ji, C., Shan, X., Wu, H., 2020. Evaluation of metal pollution-induced biological effects in Chinese shrimp Fenneropenaeus chinensis by NMR-based metabolomics. Mar. Pollut. Bull. 2020 (150), 110688.

Maisano, M., Cappello, T., Natalotto, A., Vitale, V., Parrino, V., Giannetto, A., Oliva, S., Mancini, G., Cappello, S., Mauceri, A., Fasulo, S., 2017. Effects of petrochemical contamination on caged marine mussels using a multi-biomarker approach: histological changes, neurotoxicity and hypoxic stress. Mar. Environ. Res. 128, 114-123.

Ren, X., Wang, Z., Gao, B., Liu, P., Li, J., 2017. Toxic responses of swimming crab (Portunus trituberculatus) larvae exposed to environmentally realistic concentrations of oxytetracycline. Chemosphere 173, 563-571.

Song, Q., Chen, H., Li, Y., Zhou, H., Han, Q., Diao, X., 2016. Toxicological effects of benzo (a)pyrene, DDT and their mixture on the green mussel Perna viridis revealed by proteomic and metabolomic approaches. Chemosphere 144, 214-224.

Tian, L., 2018. Spatial Distributions of Heavy Metals and as in Sediments of the Yellow River Estuary and Offshore Area and Assessment for their Ecological Risk. In Chinese. Fujian Normal University, pp. 87-88 Master thesis.

Viant, M.R., Rosenblum, E.S., Tjeerdema, R.S., 2003. NMR-based metabolomics: a powerful approach for characterizing the effects of environmental stressors on organism health. Environ. Sci. Technol. 37, 4982-4989.

Vignet, C., Cappello, T., Fu, Q., Lajoie, K., De Marco, G., Clérandeau, C., Mottaz, H., Maisano, M., Hollender, J., Schirmer, K., Cachot, J., 2019. Imidacloprid induces adverse effects on fish early life stages that are more severe in Japanese medaka (Oryzias latipes) than in zebrafish (Danio rerio). Chemosphere 225, 470-478.

Wang, H., Qiao, Y., Wang, L., 2017. Distribution and ecological risk of four heavy metals in the Tianjin coastal area of Bohai Bay, China (in Chinese). J. Hydroecol. 38 (2), 38-43.

Wang, X., Zhang, W., Chi, X., Liu, B., 2019. The heavy metals contamination in Liaodong Bay and its adjacent waters (in Chinese). Environ. Chem. 38 (10), 2317-2326.

Wen, J., Pan, L., 2015. Short-term exposure to benzo[a]pyrene disrupts reproductive endocrine status in the swimming crab Portunus trituberculatus. Comp. Biochem. Physiol. Part C 174-175, 13-20.

Xiang, D., Zhu, J., Hu, Y., Tan, F., Yang, W., 2013. Expression and function analysis of metallothionein in the testis of Portunus trituberculatus exposed to cadmium. Aquat. Toxicol. 140-141 (1-10).

Xu, L., Ji, C., Zhao, J., Wu, H., 2016. Metabolic responses to metal pollution in shrimp Crangon affinis from the sites along the Laizhou Bay in the Bohai Sea. Mar. Pollut. Bull. 113, 536-541.

Xu, Y., Jiang, T., Yang, Q., Cui, Z., Zhao, J., Qu, K., 2019. Distribution characteristics and pollution assessment of heavy metals in the surface sediments of the central region of the Bohai Sea during the summer (in Chinese). Prog. Fish. Sci. 40 (5), 52-61.

Yuan, Y., Wang, X., Jin, M., Sun, P., Zhou, Q., 2019. Influence of different lipid sources on growth performance, oxidation resistance and fatty acid profiles of juvenile swimming crab, Portunus trituberculatus. Aquaculture 508, 147-158.

Zhang, L., Liu, X., You, L., Zhou, D., Wu, H., Li, L., Zhao, J., Feng, J., Yu, J., 2011. Metabolic responses in gills of Manila clam Ruditapes philippinarum exposed to copper using NMR-based metabolomics. Mar. Environ. Res. 72, 33-39.

Zhang, G., Liu, D., Wu, H., Chen, L., Han, Q., 2012. Heavy metal contamination in the marine organisms in Yantai coast, northern Yellow Sea of China. Ecotoxicology 21 (6), 1726-1733. 